\title{
DESIGN AND FABRICATION OF ECONOMIC ELECTRIC BIKE WITH FIBER REINFORCED POLYMER COMPOSITE
}

\author{
SASIDHAR GURUGUBELLI ${ }^{1}$, DR. K. SANTARAO ${ }^{2} \&$ RAJIV ADITYA JAYANTHI ${ }^{3}$ \\ ${ }^{l}$ Mechanical Department, GMR Institute of Technology, Rajam, Andhar Pradesh, India \\ ${ }^{2}$ Mechanical Department, GMR Institute of Technology, Rajam, Andhar Pradesh, India \\ ${ }^{3}$ Mechanical Department, Cognizant, Hyderabad, India
}

\begin{abstract}
The main aim of this paper is to present the idea of harnessing the various materials and use it in today's existence of human life.The automobile industry incresingly in relying on systematic approach to material selection. There are many materials available but the selection of particular material is the first and most important factor. Fiber Reinforced Plastic Polymer are among one of the preferred and satisfying alternative in terms of Light Weight, Impact Strength, Tensile Strength, Non Corrosive, Easy molded character. The effective characteristic of less weight the efficiency of an automobile increases, simultaneously emissions of carbon gradually reduces. Which is a desired agenda of todays automotive field. In this paper, weperformed some of the design calculations and fabricated the main body of electric bike which involves Fuel tank, Mud Guard front and Mud guard rear, Front faring cowl, lower Fairing and Side fairings to subjected to various tests to ivestigate its properties under various conditions.

KEYWORDS: Fiber Reinforced Plastic Polymer, Automobile Indistry, Alternative, Impact Strength \& Tensile Strength
\end{abstract}

Received: Jun 09, 2020; Accepted: Jun 29, 2020; Published: Jul 18, 2020; Paper Id.: IJMPERDJUN2020387

\section{INTRODUCTION}

Globally the automobile field is always subjected to significant developments, changes and inventions. Manufacturing of light weight vehicles are the most challenging and important mission. Polymers enhance not only the less mass agenda but also they offer the strength standards and requirements. They are prefferable compared to the convenctional vehicles and components. Keeping in mind Environment and its safety, the carbon emissions should be comparitively reduced and Fuel efficiency should be increased that can be acheived with single application. Fiber Reinforced Plastic Polymer can be applied in structural and non structural components. The creation and application of this materials will further stimulates the use of these advanced materials in Automobiles. Performance, Benfit of the environment,Numerous cost and Commercial appilcation can be acheived.

As per the requirement we choosen

Fiber Reinforced Polymer.

Epoxy Resin.

Activator/Hardner.

Fibre Reinforced Polymers (FRP): They are also known as "composites" are materials composed of fibres reinforcements and a polymer resin. The reinforcements impart strength and stiffness, while the resin is an adhesive matrix that bonds the fibres. In the finished part, the resin matrix transfers applied loads to the reinforcing fibres and protects the fibres from environmental attack [1]. 
FRP composites offer many advantages compared to traditional materials, including:

- High Strength

- $\quad$ Light weight

- Corrosion resistance

- Durability

- Design flexibility

- Part consolidation

- Dimensional stability

- Low thermal conductivity

FRP composites are composed of fibre reinforcements and a resin matrix that bonds the fibres shown in figure 1. Such composites can also include core materials, fillers, and other additives to provide unique performance attributes. Many types of resins, reinforcements, core materials, and additives can be combined to design very specific properstie within FRP products.

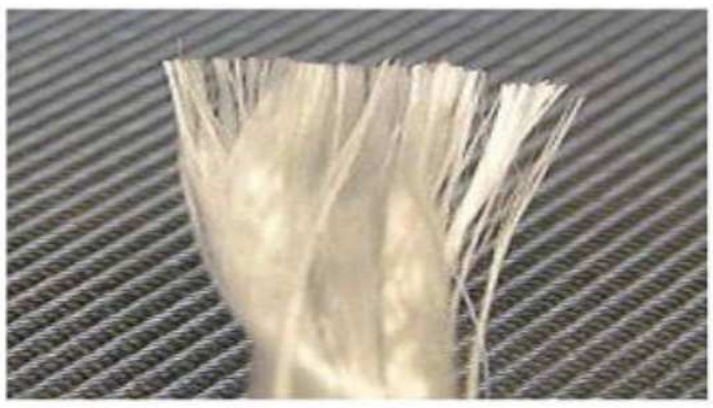

Figure 1: FRP Composite

\section{Classification of FRPs}

The major classes of FRP and their inherent physical properties are depicted in Table 1 while their chemical composition is tabulated in Table2 The physical properties of different FRPs [2].

Table 1: Classifications of FRPs

\begin{tabular}{|l|l|}
\hline \multicolumn{1}{|c|}{ Classes of FRP's } & \multicolumn{1}{c|}{ Physical properties } \\
\hline A glass & High durability, strength and electrical resistivity \\
\hline C glass & High corrosion resistance \\
\hline D glass & Low dielectric constant \\
\hline E glass & Higher strength and electrical resistivity \\
\hline AR glass & Alkali resistance \\
\hline R glass & Higher strength and acid corrosion resistance \\
\hline S glass & Higher tensile strength \\
\hline
\end{tabular}

Table 2: Chemical composition of various classes of glass fibers

\begin{tabular}{|l|l|l|l|l|l|l|l|l|l|}
\hline \multicolumn{1}{|c|}{ Type of $\mathbf{G F}$} & $\mathbf{S i O}_{\mathbf{2}}$ & $\mathbf{A l}_{\mathbf{2}} \mathbf{O}_{\mathbf{3}}$ & $\mathbf{F e}_{\mathbf{2}} \mathbf{O}_{\mathbf{3}}$ & $\mathbf{T i O}_{\mathbf{2}}$ & $\mathbf{B}_{\mathbf{2}} \mathbf{O}_{\mathbf{3}}$ & $\mathbf{C a O}$ & $\mathbf{M g O}$ & $\mathbf{N a}_{\mathbf{2}} \mathbf{O}$ & $\mathbf{K}_{\mathbf{2}} \mathbf{O}$ \\
\hline E-glass & 55 & 14 & - & 0.2 & 7 & 22 & 1 & 0.5 & 0.3 \\
\hline C-glass & 64.6 & 4.1 & - & - & 5 & 13.4 & 3.3 & 9.6 & 0.5 \\
\hline
\end{tabular}




\begin{tabular}{|l|l|l|l|l|l|l|l|l|l|}
\hline S-glass & 65 & 25 & - & - & - & - & 10 & - & - \\
\hline A-glass & 67.5 & 3.5 & - & - & 1.5 & 6.5 & 4.5 & 13.5 & 3 \\
\hline R-glass & 60 & - & - & - & - & 9 & 6 & 0.5 & 0.1 \\
\hline EC-Glass & 58 & 12.4 & & - & - & 23 & & - & - \\
\hline
\end{tabular}

\section{DESIGN CALCULATIONS}

Design calculations of some of the important parts of the electric bike are discussed in this section.

\section{Motor Calculations}

- Motor Specifications are as given below:

- Motor model - BLDC(Brushless Direct Current) 125/2D-1

- $\quad$ Power - 1000watts

- Continuous torque $-3.2 \mathrm{~N}-\mathrm{m}$

- $\quad$ Peak torque -8 N-m

- $\quad$ DC voltage $-48 \mathrm{v}$

- $\quad$ Rated current - 22 amp

- $\quad$ Peak current - 30 amp

- Here three phases $[\mathrm{A}, \mathrm{B}, \mathrm{C}]$ of BLDC motor

$$
\begin{aligned}
& \mathrm{V}_{\mathrm{a}}=\mathrm{RI}_{\mathrm{a}}+\mathrm{L}\left(\mathrm{d}_{\mathrm{ia}} / \mathrm{dt}\right)+\mathrm{e}_{\mathrm{a}} \\
& \mathrm{V}_{\mathrm{b}}=\mathrm{RI}_{\mathrm{b}}+\mathrm{L}\left(\mathrm{d}_{\mathrm{ib}} / \mathrm{dt}\right)+\mathrm{e}_{\mathrm{b}} \\
& \mathrm{V}_{\mathrm{c}}=\mathrm{RI}_{\mathrm{c}}+\mathrm{L}\left(\mathrm{d}_{\mathrm{ic}} / \mathrm{dt}\right)+\mathrm{e}_{\mathrm{c}} \\
& \mathrm{E}=\mathrm{e}_{\mathrm{a}}=\mathrm{e}_{\mathrm{b}}=\mathrm{e}_{\mathrm{c}} \\
& \mathrm{I}=\mathrm{i}_{\mathrm{a}}=\mathrm{i}_{\mathrm{b}}=\mathrm{i}_{\mathrm{c}}
\end{aligned}
$$

Where, Va, Vb,Vc are phase voltages, ia, ib, ic are phase currents, Ra, Rb, Rc are phase resistances, ea, eb, ec are back emf's of a,b,c phases and L, R are self inductances \& armature resistance respectively [3].

Electromagnetic torque, $\mathrm{T}_{\mathrm{e}}=\frac{1}{\omega}\left[\mathrm{e}_{\mathrm{a}} \mathrm{i}_{\mathrm{a}}+\mathrm{e}_{\mathrm{b}} \mathrm{i}_{\mathrm{b}}+\mathrm{e}_{\mathrm{c}} \mathrm{i}_{\mathrm{c}}\right]$

$$
\mathrm{T}_{\mathrm{e}}=\frac{1}{\omega}[3 \mathrm{EI}]
$$

Rated current $(\mathrm{I})=22 \mathrm{amps}$

$\operatorname{Back} \operatorname{emf}(\mathrm{E})=48 \mathrm{v}$

Back emf equals the terminal voltage. Then speed reaches maximum. 


$$
\begin{aligned}
\mathrm{T}_{\mathrm{e}} & =\frac{1}{(2 \pi \mathrm{N} / 60)}[3 \mathrm{EI}] \\
& =\frac{60}{2 \times \pi \times 3000}[3 \times 48 \times 22]=\frac{3168}{314} \\
\mathrm{~T}_{\mathrm{e}} & =10.08 \mathrm{~N}-\mathrm{m}
\end{aligned}
$$

Here $\mathrm{N}=3000 \mathrm{rpm}, \omega=\frac{2 \times \pi \times 3000}{60}=314 \mathrm{rad} / \mathrm{sec}$

$$
\text { Voltage constant, } \begin{aligned}
\mathrm{k}_{\mathrm{v}} & =\frac{\omega_{\text {no load }}}{\mathrm{V}_{\text {peak }}} \\
& =\frac{3000}{48} \\
& =6.54 \mathrm{rad} \mathrm{s}^{-1} / \mathrm{v}
\end{aligned}
$$

Back emf constant or speed constant, $\mathrm{ke}=\mathrm{E}_{\mathrm{b}} / \omega=1 / \mathrm{k}_{\mathrm{v}}=0.15 \mathrm{v} / \mathrm{rad} \mathrm{s}^{-1}$

Friction Coefficient (B) is, At constant speed

$$
\begin{aligned}
\mathrm{T}_{\mathrm{e}} & =\mathrm{B} \omega \\
10.8 & =\mathrm{B} \times 2 \pi \mathrm{N} / 60 \\
10.8 & =\mathrm{B} \times 2 \times \pi \times 3000 / 60 \\
\mathrm{~B} & =\frac{10.8 \times 60}{2 \times \pi \times 3000} \\
& =0.03 \mathrm{~N}-\mathrm{m} \mathrm{sec} / \mathrm{rad}
\end{aligned}
$$

"B" varies with speed, Here back emf displaced $120^{\circ}$ from one phase to another phase

\section{Current at full load condition is}

$$
\begin{aligned}
& \mathrm{IFL}=\text { rated power } /(1.732 \times \mathrm{V} \times \mathrm{PF} \times \eta) \\
& \mathrm{IFL}=10001.732 \times 48 \times 0.43 \times 0.8 \\
& =34.96 \mathrm{amps}[\cong 30 \mathrm{amps}=\text { peak current }]
\end{aligned}
$$

Torque at full load conditions

$$
\begin{aligned}
& \text { Input power }=\text { output power } \\
& \text { Voltage } \times \text { current }=\text { torque } \times \text { angular velocity } \\
& \mathrm{V} \times \mathrm{I}=\tau \times 2 \pi \mathrm{N} / 60 \\
& \tau_{\mathrm{FL}}=(48 \times 34.96) / 314 \\
& =5.34 \mathrm{~N}-\mathrm{m}
\end{aligned}
$$

[Actually peak torque is $8 \mathrm{~N}-\mathrm{M}$ ] $\tau \mathrm{FL}>5.34 \mathrm{~N}-\mathrm{m}$

Load factor $(\mathrm{LF})=\mathbf{8 0 0} 1000 \times 100=80 \%$ load

\section{Performance of Motor at Steady State}

$\mathrm{Kt}=\mathrm{Kv} \times 1.345$ i.e., already known. 
Current at steady state conditions

$\mathrm{I}=[\mathrm{V}-(\mathrm{Kv} \times \mathrm{rpm})] / \mathrm{R}$

Taking line - line resistance as $0.095 \Omega$

Phase resistance $=0.04{ }^{\prime} \Omega$

Torque at steady state of motor

$$
\begin{aligned}
\tau=(\mathrm{Kt} & \times \mathrm{I})-(\mathrm{Kt} \times \mathrm{INL}) \\
& =(0.14 \times 22)-(0.14 \times 0.54) \\
& =3.0044 \mathrm{~N}-\mathrm{m}
\end{aligned}
$$

\section{Current at peak motor efficiency}

$$
\begin{aligned}
\mathrm{I} & =\sqrt{\mathrm{V}} \times \mathrm{I}_{\mathrm{NL}} / \mathrm{R} \\
& =\sqrt{48} \times 0.54 / 0.04 \\
& =24.4 \mathrm{amps}
\end{aligned}
$$

\section{Transmission Calculations [4]}

Required bike speed $=45 \mathrm{~km} / \mathrm{hr}$

$$
\begin{aligned}
& =45 / 60 \mathrm{~km} / \mathrm{min} \\
& =\left(45 \times 10^{5}\right) / 60 \mathrm{~cm} / \mathrm{min} \\
& =\left(45 \times 10^{5}\right) /(2 \times \pi \times 30 \times 60) \mathrm{rpm} \\
& =398 \mathrm{rpm} \cong 400 \mathrm{rpm}
\end{aligned}
$$

Rear wheel sprocket speed $=400 \mathrm{rpm}=\mathrm{N} 2$

Number of teeth or rear sprocket $=39=\mathrm{Z} 2$

Number of teeth or front sprocket $=14=Z 1$ [At output shaft of gear box]

Transmission ratio $(\mathrm{i})=\mathrm{Z} 2 / \mathrm{Z} 1=\mathrm{N} 1 / \mathrm{N} 2$

$$
\begin{aligned}
& =39 / 14=N 1 / 400 \\
& \mathrm{~N} 1=1114 \mathrm{rpm}
\end{aligned}
$$

\section{Progression ratio $(\varnothing)=2000 / 1114$ rpm}

Where, Input motor shaft rotates of $2000 \mathrm{rpm}$,

$$
\therefore \varnothing \text { (or) } \mathrm{i}=1.8=Z 2 / 18=\mathrm{Z} 2=33 \text { (Gear ratio) }
$$

\section{Gear Ratios and Sprocket Ratios}

Pinion teeth $(\mathrm{Z} 1)=18$

Gear teeth $(\mathrm{Z} 2)=42$

$\therefore$ Gear ratio $(\mathrm{i})=33 / 18=1.83$ 
Front sprocket $(\mathrm{Z} 1)=14$

Rear sprocket $(Z 2)=39$

$\therefore$ Sprocket ratio $=39 / 14=2.78$

For acceleration: Increase the gear ratio

Tooth of rear sprocket by (+2) and front sprocket by (-1)

For top speed : Decrease the gear ratio

Tooth of rear sprocket by (-1) and front sprocket by (+2)

\section{Battery Calculations [6]}

Here we know that, Power $=$ voltage $\times$ current

$$
\begin{aligned}
& 1000=48 \times \mathrm{I} \\
& \therefore \mathrm{I}=20.8 \mathrm{Ah}
\end{aligned}
$$

For $1 \mathrm{KW}$ i.e., 1000 watts motor of $48 \mathrm{~V}$ capacity we have to select batteries of $20.83 \mathrm{Ah}$

\section{6. $\quad$ Electrical Charging}

Here AC supply 48V \& 20.83 Ah

$$
\begin{aligned}
& \mathrm{P}=\mathrm{V} \times \mathrm{I} \\
& \mathrm{P}=48 \times 20.83 \\
& \mathrm{P}=999.84 \mathrm{~W} \cong 1000 \text { watts } \\
& \therefore \text { Time required charging the battery completely } \\
& \mathrm{t}=\mathrm{p} \times \mathrm{nW} \\
& =1000 \times 41000 \\
& =4 \mathrm{hr} \\
& \therefore \mathrm{t}=4 \mathrm{hrs}
\end{aligned}
$$

\section{BODY OF ELECTIC BIKE FABRICATION PROCESS}

The Manufacturing processes used to produce FRP composite parts can accommodate a one-time moulded part or high production quantities. The two most commonly used open moulding techniques are hand layup and spray up, but vacuumassisted resin-transfer moulding processes are becoming more common. These methods are adaptable to custom work or low-to-medium production volumes. Since there are ways of fabrication in FRP, we fabricated the body works using “OPEN MOULDING” technique [1][6][7].

\section{Open Moulding}

A single mould that produces a one-sided finish is an open mould. Tooling cost for open moulds is relatively low, making it possible to use this technique for short production runs. Generally a male pattern or model is built, from which a female 
mould is fabricated. A number of materials can be used to construct moulds depending on the shape and quantity of the desired part. The surface of the mould is prepared with a wax or release agent which allows the part to separate from the mould at the end of the lamination asshown in the figure 2 . The longevity of a mould varies and may be a significant cost factor depending on part complexity, material, and cycle time.

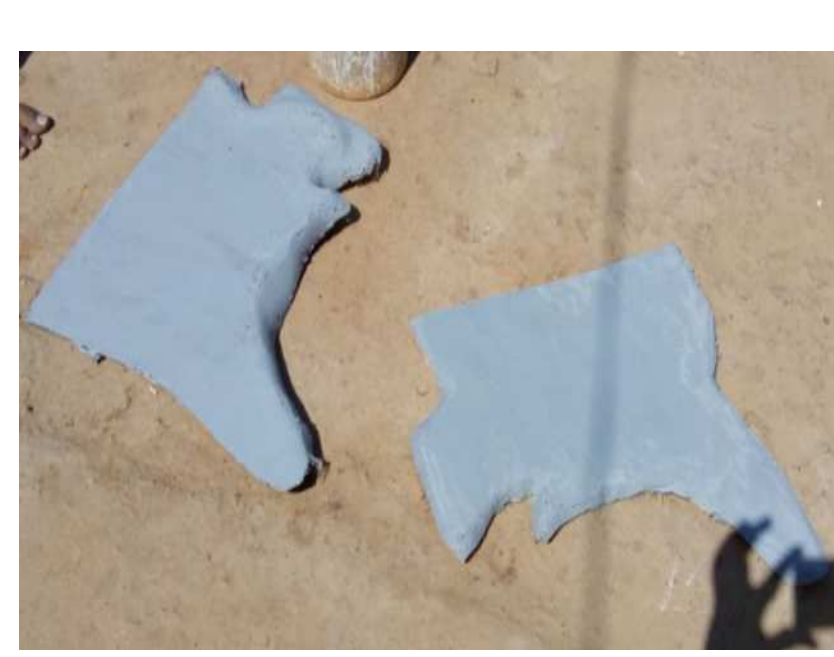

Figure 2: Moulds of the body

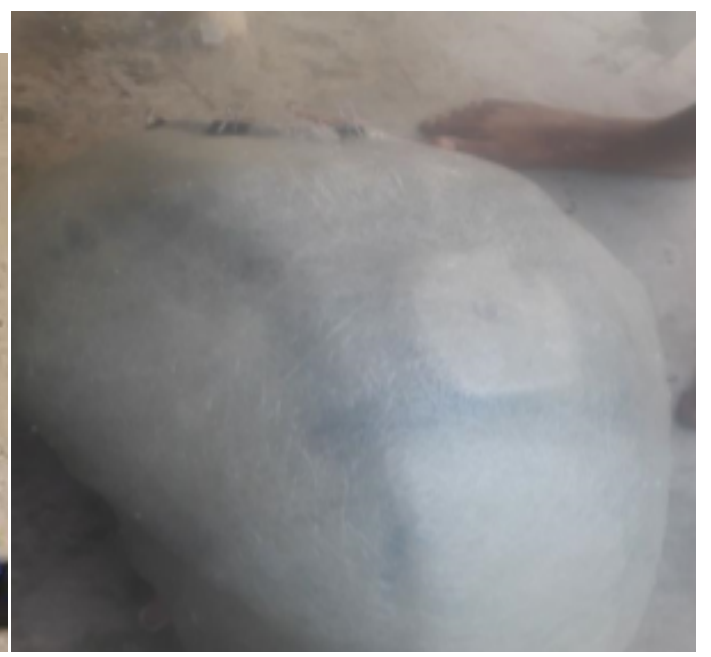

Figure 3. Hand layout of the bike tank

\section{Hand Lay-up:}

Hand layup refers to the consolidation of the resin fibres using hand tools such as brushes, rollers, and squeegees. The equipment required for hand layup simply consists of a mould and hand tools. High quality parts can be manufactured in this process. The ultimate quality depends upon the skill of the laminators, specifically with regard to the dispensing of the amount of resin and the ratio of resin to reinforcement. The materials commonly used in hand layup consist of thermoset resins in combination with chopped strand mat, textile fabric, woven or knitted reinforcements, and sometimes a structural core. The process is accomplished by first applying a cosmetic surface such as gel coat to the properly prepared mould. Bike fuel tank is prepared by this hand layup method which is shwn in the figure 3 .

Next, the pattern-cut glass reinforcement is placed in the mould and impregnated with the proper amount of resin. The resin can be applied by brush or paint roller from containers of initiated resin or from a spray gun which combines the resin and catalyst in the precise proportion. Once the glass reinforcement is fully saturated or "wet out," the laminate is compacted with specially designed rollers and brushes to remove air bubbles and distribute the resin evenly [8][9]. Multiple layers, or plies, of laminate are built up in sequence, often with a core material in the middle, to reach the desired thickness. Various inserts, ribs, fasteners, or other items can be incorporated in the moulded part. Following a curing cycle, the part is de-moulded and trimmed as required. 


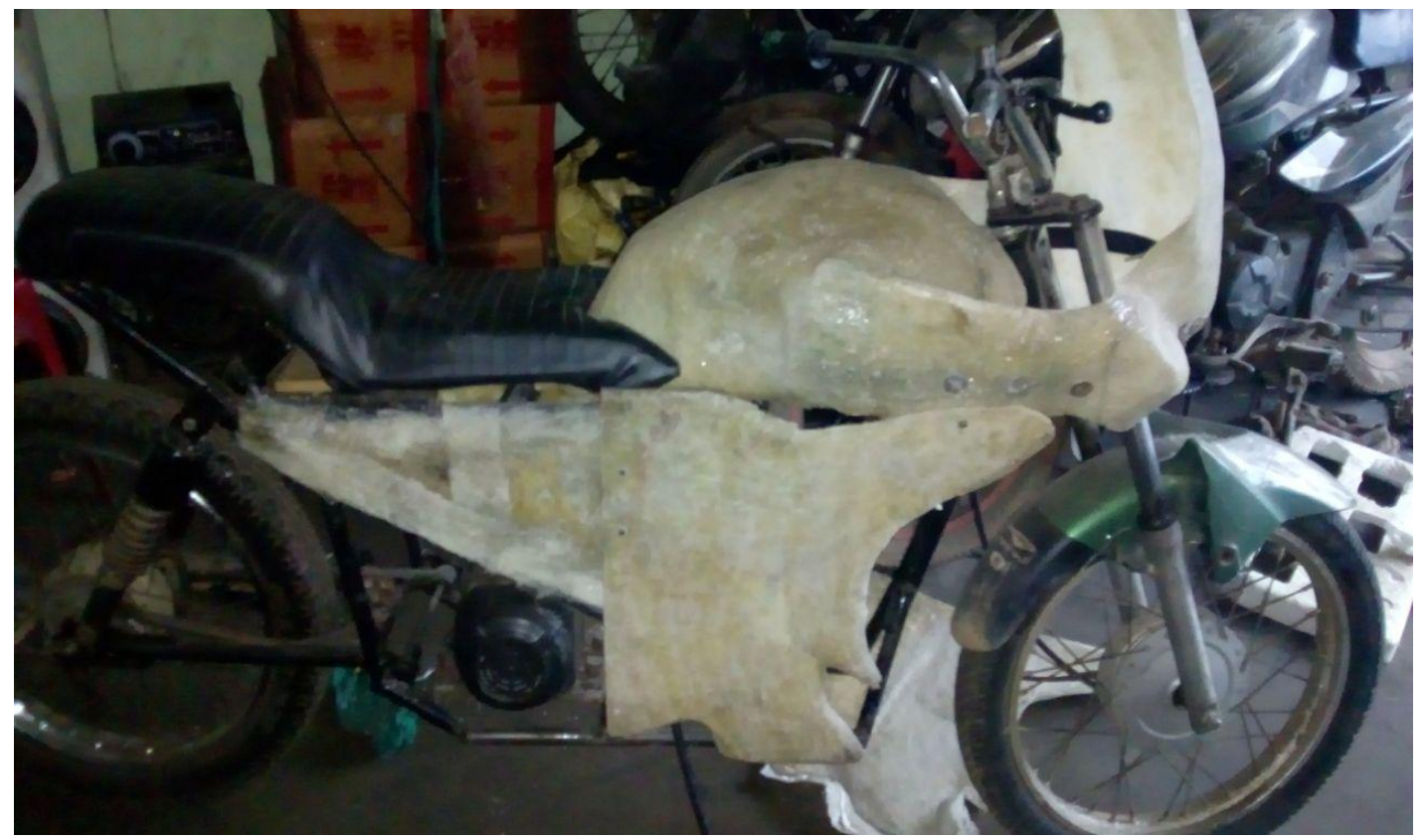

Figure 4: Bike after Installing Body Works made with FRP

After the body works are installed to the bike shown in figure 4, there are some finishing operations are also needed to be performed to give a better appearance and for the smooth handling. After all these finishing processes like polishing, painting etc, the bike is as depicted in the figure 5 .

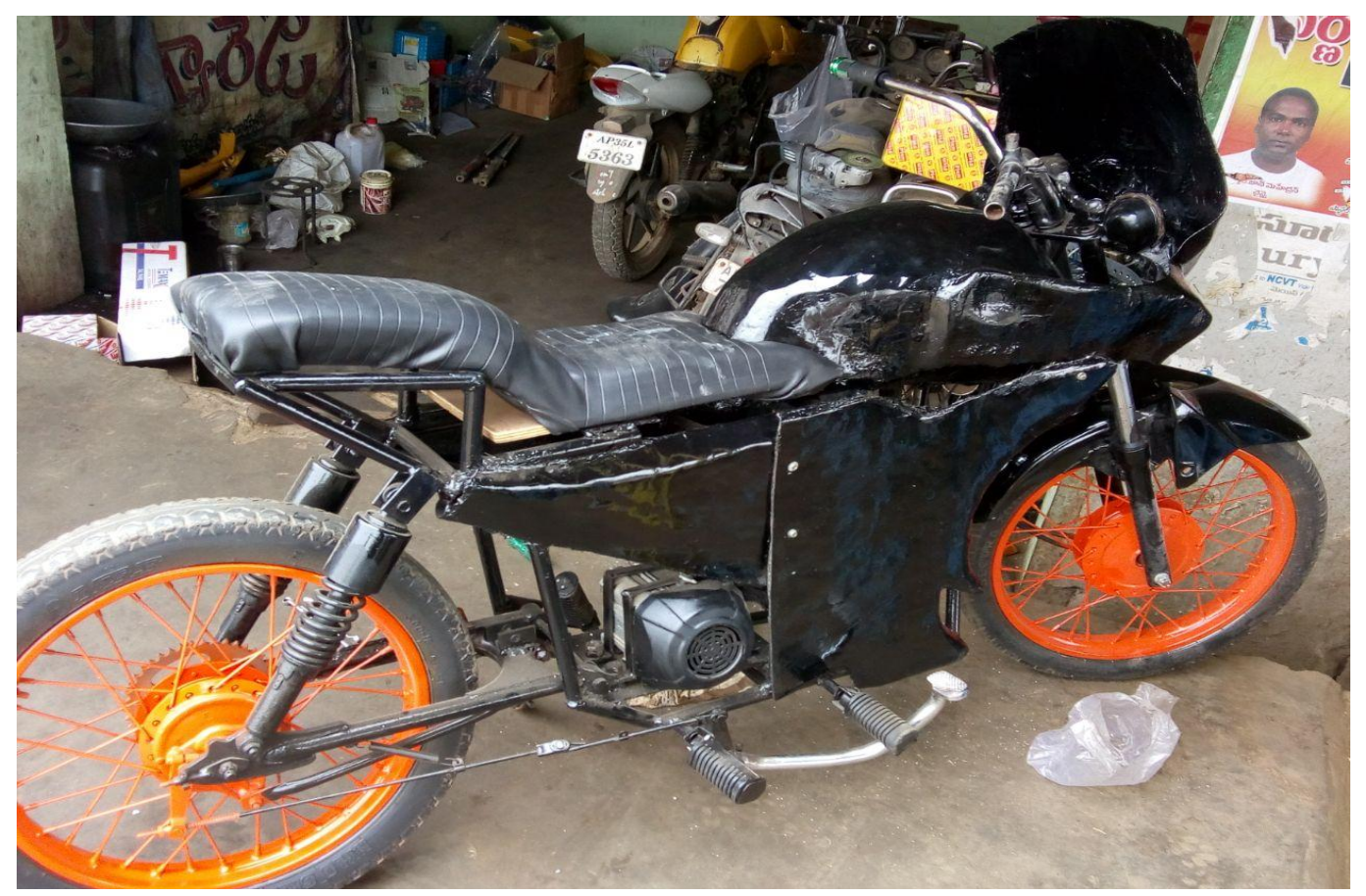

Figure 5: Bike after the Finishing Operations

\section{CONCLUSIONS}

Due to the eradication of the natural resources and over consumption of the fossils fuels there may be a grave danger for the future generations. This paper discussed that with the help of this electric bike these problems will be minimized. This electric motor bike can run at an average speed of 40kmph. The bike can easily climb at slope of 30 degrees. The battery 
can be charged in single mode electrical supply. The cost is less and it is very economical. The body works are noncorrosive and economical.

The bike is totally eco friendly, non- polluted and there is no running cost for battery and is absolutely recommended for local use. By this study we conclude with various analysis tests theoretically as well as experimentally that our low carbon steel bike frame can with stand a load up to $2000 \mathrm{~N}$ without deflection and the material can be shock resistant and it can support two to three persons riding without fail. This design will support smooth riding and absorb fewer amounts of vibrations and sudden impacts.

The bike was found that it requires 4 hrs to get charged battery completely the discharge time of battery theoretically is $2 \mathrm{hrs}$, the bike was tested on plane flat road the maximum speed of the bike is $40 \mathrm{kmph}$ and it could be obtained even more than $40 \mathrm{kmph}$ on plane road with slope of 15 and 30 degrees respectively. Due to fair torque and speed it will support dual riding. The body works which were carried are absolutely less in weight parameter and even exhibiting high strength and toughness.

\section{REFERENCES}

1. S. Matey, D. R. Prajapati, K. Shinde, A. Mhaske, and A. Prabhu, "Design and fabrication of electric bike," Int. J. Mech. Eng. Technol., vol. 8, no. 3, pp. 245-253, 2017.

2. R. Sasikumar, "Fabrication and Mechanical Behavior Study of Fiber Reinforced Composites for Automobile," no. December, 2017.

3. S. Raghunath, "Hardware Design Considerations for an Electric Bicycle Using a BLDC Motor," no. June, pp. 1-24, 2014.

4. Jweeg, Muhsin J., Abdul-Kareem F. Hasan, And Jawad K. Zeboon. "Investigation Of Impact Response For Cfrp/Steel Hybrid Composite Plate Under Low-Velocity Impact." International Journal of General Engineering and Technology (IJGET) 3,.2, Mar 2014, 1-10

5. M. Sharma, A. Verma, G. Tiwari, S. Singh, and M. Nadeem, "Design and Fabrication of Regenerative Electric Bike," vol. 6, no. 5, pp. 5140-5143, 2016.

6. A. N. Jadhav and V. A. Kulkarni (Deodhar), "Simulation and analysis of solar powered Brushless Dc Motor," Int. J. Sci. Technol. Res., vol. 9, no. 1, pp. 31-35, 2020.

7. Habeeb, Majeed A. "Effect of Nanosilver Particles on Thermal and Dielectric Properties of (PVA-PVP) Films." International Journal of Applied and Natural Sciences 2.4 (2013): 103-108.

8. A.Karthick, K. Prabu, J. V, K. Praveen, and K. P., "Experimental Investigation of Glass Fiber Reinforced Polymer ( Gfrp ) Composite Laminates," Ijsdr, vol. 2, no. 4, pp. 135-154, 2017.

9. N. Nagar and A. Nagari, "Design and Fabrication of Low Cost Solar," pp. 465-481, 2013.

10. Reddy, T. BALARAMI. "Mechanical performance of green coconut fiber/HDPE composites by using flexural strength." International Journal of Mechanical Engineering (IJME), 3 (1), 5366 (2014).

11. M. M. Trivedi, M. K. Budhvani, K. M. Sapovadiya, D. H. Pansuriya, and D. Chirag, "Design \& Development of E-Bike - A Review," Des. Dev. E-Bike - A Rev. Mitesh, vol. 1, no. 5, pp. 36-43, 2017. 
12. Ismail, Mahmud Rasheed, Z. A. A. A. Ali, and Muhannad Al-Waily. "Delamination damage effect on buckling behavior of woven reinforcement composite materials plate." International Journal of Mechanical \& Mechatronics Engineering IJMMEIJENS 18.05 (2018): 83-93.

13. S. Vanangamudi, S. Prabhakar, C. Thamotharan, and R. Anbazhagan, "Design and fabrication of dual clutch," Middle - East J. Sci. Res., vol. 20, no. 12, pp. 1816-1818, 2014. 